rev.relac.int.estrateg.segur.13(1):163-192,2018

\title{
El regionalismo asimétrico como eje de la resistencia sudamericana a Brasil (2000-2013)*
}

\author{
Rita Giacalone $^{* *}$
}

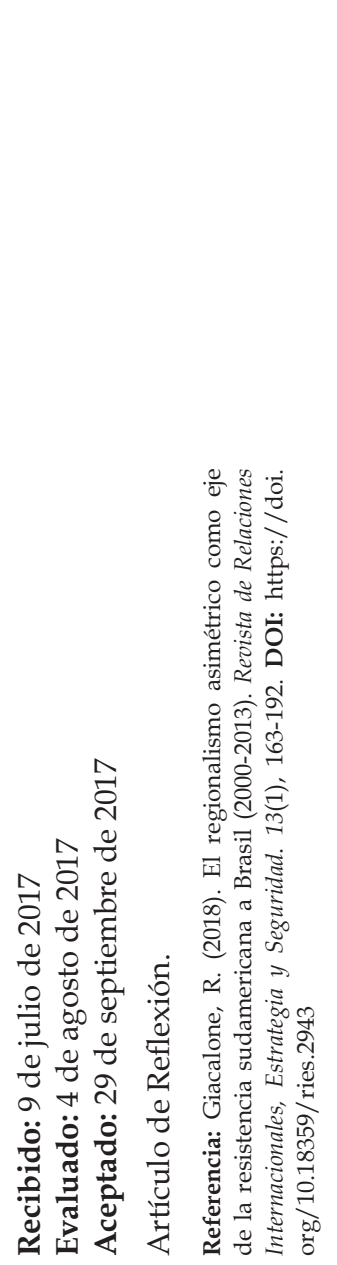

\section{Resumen}

El regionalismo siempre crea tensiones entre sus miembros por su carácter asimétrico, pero en Sudamérica el regionalismo brasileño posee rasgos realistas, constructivistas e institucionalistas que enfatizan la asimetría con sus vecinos. Como resultado, las organizaciones construidas para apoyar la proyección regional y global de Brasil generaron resistencia en Gobiernos sudamericanos entre 2000 y 2013. Los objetivos de este artículo son analizar esa resistencia en Chile, Argentina y Venezuela; identificar los factores sistémicos, normativos y externos que la posibilitaron y sus etapas, y vincular la resistencia con paradigmas globales del regionalismo. Como metodología se utili-

Este artículo forma parte del proyecto de investigación Geopolitical and Geo-economic Implications of the Architecture of Latin American Regionalism since the Beginning of the $21^{\text {st }}$ Century, que se adelanta en el Centro de Estudios Latinoamericanos de la Universidad de Calgary, Canadá.

** Ph.D. en Historia, Indiana University. Profesora titular de Historia Económica, Facultad de Ciencias Económicas y Sociales, Universidad de Los Andes, Venezuela; profesora invitada del Postgrado de Integración Regional, Universidad de La Plata, Argentina, e investigadora asociada del Centro de Estudios Latinoamericanos, Universidad de Calgary, Canadá. Correo electrónico: ritagiacalone@ hotmail.com; ritagiacalone@yahoo.com 
zó la revisión documental para los primeros objetivos y el análisis del discurso, como técnica de investigación cualitativa, para inferir motivaciones y vinculación con paradigmas del regionalismo. Entre los resultados se destaca que existen factores sistémicos resultado de la experiencia histórica sudamericana que explican el surgimiento y mantenimiento de la resistencia. Esta puede dividirse en etapas (2000-2004, 2005-2010, 2011-2013), según las estrategias utilizadas, y se vincula al hecho de que el regionalismo brasileño sigue el paradigma región-céntrico y sus vecinos prefieren el de la multipolaridad descentralizada.

Palabras clave: regionalismo asimétrico; estrategias de resistencia; política exterior; Brasil; Sudamérica.

\title{
Asymmetric regionalism as the axis of South American resistance to Brazil (2000-2013)
}

\begin{abstract}
Regionalism always creates tensions among its members due to its asymmetrical character, but in South America, Brazilian regionalism has realistic, constructivist, and institutional features that emphasize asymmetry with its neighbors. As a result, organizations built to support Brazil's regional and global projection generated resistance in South American governments between 2000 and 2013. The objectives of this article are to analyze this resistance in Chile, Argentina, and Venezuela; to identify the systemic, normative, and external factors that enabled it and its stages, and link resistance with global paradigms of regionalism. As a methodology, the documentary review was used for the first objectives and discourse analysis, as a qualitative research technique, to infer the motivations and link with paradigms of regionalism. Among the results, it is highlighted that systemic factors are arising from South American historical experience that explains the emergence and maintenance of resistance. This can be divided into stages (2000-2004, 2005-2010, 20112013) according to the strategies applied, and it is linked to the fact that Brazilian regionalism follows the region-centric paradigm, and its neighbors prefer decentralized multipolarity.
\end{abstract}

Keywords: asymmetric regionalism; resistance strategies; foreign policy; Brazil; South America. 


\section{Regionalismo assimétrico como o eixo de resistência da América do Sul para o Brasil (2000-2013)}

\section{Resumo}

O regionalismo cria tensões entre os membros devido ao seu caráter assimétri$\mathrm{co}$, mais o regionalismo do Brasil tem traços realistas, construtivistas e institucionalistas que enfatizam a assimetria com seus parceiros sul-americanos. Em consequência, as organizações desenvolvidas pelo Brasil para projetar-se regionalmente e globalmente produziram resistência entre os governos sul-americanos entre 2000 e 2013. Nossos objetivos são: 1) analisar a resistência no Chile, Argentina e Venezuela, 2) identificar os fatores sistêmicos, normativos e externos que possibilitaram a resistência e a fases de resistência e 3) ligar a resistência sul-americana com paradigmas globais do regionalismo. Metodologicamente, o artigo combina revisão documental e análise qualitativa do discurso para inferir as motivações dos governos do Chile, Argentina e Venezuela e suas ligações com paradigmas globais do regionalismo. Entre os resultados, o artigo evidencia os fatores sistêmicos nascidos do histórico da América do Sul. Resistência é dividida em fases (2000-2004, 2005-2010, 2011-2013), de acordo com as diferentes estratégias aplicadas, e está ligada ao fato de que, enquanto o regionalismo brasileiro segue o paradigma centrado na região, seus vizinhos preferem o paradigma multipolar descentralizado.

Palavras-chave: regionalismo assimétrico; estratégias de resistência; política externa; Brasil; América do Sul.

\section{Introducción}

En ausencia de mecanismos correctivos, el regionalismo siempre crea tensiones entre sus miembros por su carácter asimétrico. El regionalismo brasileño posee características que lo asemejan al regionalismo asimétrico de China en el sudeste asiático (Beeson, 2010). Brasil representa casi el 50\% del producto interno bruto (PIB) sudamericano, ejecuta una política regional proactiva y considera a la región una plataforma para vincularse con economías emergentes y foros como la Orga- nización Mundial del Comercio (OMC) (Riggirozzi, 2010, pp. 9 y 10). Esta asimetría se manifiesta en el hecho de que las organizaciones regionales creadas por Brasil para apoyar su proyección regional (Mercado Común del Sur [Mercosur] y Unión de Naciones Sudamericanas [Unasur]) buscan alcanzar objetivos nacionales brasileños o impedir que se alcancen otros intereses. En este sentido, es ilustrativo que:

Al proyecto brasileño le repugna la integración hemisférica [...], los tratados bilaterales de libre comer- 
cio e incluso el acuerdo MercosurUnión Europea [UE] [...], todas estas posibilidades [...] comprometen la vocación industrial del país, bien supremo de la representación política y del interés nacional. (Cervo, 2009, p. 85, en Bernal-Meza, 2013, nota 33)

Womack $(2007,2016)$ y Granja Hernández (2013) agregan elementos a la descripción realista del regionalismo asimétrico. Womack (2007) destaca la importancia de la percepción mutua (constructivismo) en la relación entre miembros grandes y pequeños, porque los segundos mantendrán la relación si perciben que les brinda beneficio o los protege de amenazas. En 2016, el mismo autor plantea que la existencia de regiones, entre la soberanía nacional y la interacción global, crea problemas característicos de las relaciones entre vecinos regionales. Según Granja Hernández (2013), aunque Mercosur obliga a tomar decisiones por consenso, esas decisiones están determinadas por negociaciones bilaterales Argentina-Brasil, lo que hace que sus políticas domésticas y objetivos de política exterior afecten la institucionalidad del acuerdo (institucionalismo).

Wehner (2015) y Malamud (2011, 2016a) trataron el tema de la resistencia al regionalismo brasileño. El primero utiliza "role theory" para explicar por qué Argentina, Chile y Venezuela enfrentaron el regionalismo de Brasil, y concluye que se debió a la existencia de diferentes visiones de la región y lo regional. Malamud (2011) destaca que el liderazgo regional brasileño no atrajo apoyo de sus vecinos por rivalidades de poder y escasez de recursos materiales, aunque ellos no objetaron su liderazgo global. Asimismo, agregaba que esos vecinos aceptan su liderazgo debido a compensaciones materiales, pero son lentos para seguirlo o prefieren crear sus propias organizaciones regionales por la emergencia de otros centros de poder (multipolaridad descentralizada) (2016a). Además, aunque económicamente el regionalismo no produzca beneficios, resulta útil como instrumento de política exterior para alcanzar objetivos políticos (proyección internacional, estabilidad regional, legitimidad externa) (Malamud, 2016a).

Flemes y Wehner (2012) analizan las motivaciones de Argentina, Chile, Colombia y Venezuela para limitar el liderazgo regional brasileño y consideran que la contestación relativa (mediante el soft power) es la estrategia más utilizada para hacerlo. Contestación significa 'desacuerdo', por lo que descartan la posibilidad de estrategias conflictivas ya que consideran a Sudamérica una zona de paz negativa. En ese contexto, enfatizan la importancia de actores domésticos para explicar las diferencias en estrategias.

El presente artículo reconoce aportes de esos estudios previos $y$, en especial, los de Flemes y Wehner (2012) y Malamud (2016a). Entre los de Flemes y Wehner se encuentran: 1) plantear el análisis de las formas que asume la contestación del poder regional entre potencias secundarias; 2) identi- 
ficar carencias de la política regional brasileña (incapacidad para construir instituciones regionales democráticas e inclusivas); 3) identificar que Chile no resiste el poder de Brasil, sino su proyecto regional, y 4) enfatizar el rol de la Alianza del Pacifico (AP) como mecanismo para balancear la alianza argentino-venezolana.

Los aportes de Malamud (2016a) son: 1) destacar rivalidades de poder y escasez de recursos materiales brasileños para que su regionalismo sea aceptable para sus vecinos; 2) identificar la preferencia de esos últimos por sus propias organizaciones regionales $y$ el rol de ellas como instrumentos de política exterior, y 3) vincular el regionalismo sudamericano con la multipolaridad descentralizada.

Sin embargo, este artículo se distancia de ambas publicaciones porque: 1) analiza un aspecto específico de la contestación relativa -la resistencia (negación a aceptar algo)-; 2) la vincula con un elemento concreto de la hegemonía brasileña -su regionalismo-; 3) entiende que los factores sistémicos no derivan de relaciones de poder en el sistema internacional, sino del contexto histórico regional y se manifiestan en elementos económicos (poca interdependencia comercial), políticos (creación de acuerdos regionales que expresan intereses nacionales) y culturales (conceptos normativos como soberanía), y 4) asocia el regionalismo brasileño y la resistencia con interpretaciones globales del regionalismo que varían a lo largo del periodo analizado.
El presente trabajo profundiza la relación entre regionalismo brasileño y resistencia en tres estudios de caso (Chile, Argentina, Venezuela). Con esto se busca ampliar la comprensión de las relaciones intrasudamericanas y redefinir los factores sistémicos que la inspiran como derivados de la tradición histórica regional, antes que de su ubicación relativa en el sistema internacional. Se explora así una dimensión regional de la política exterior en Sudamérica, que aprovecha una coyuntura permisiva del contexto global para que los Gobiernos ejerciten su agencia en las relaciones entre ellos. Como el análisis corresponde a un periodo y grupo de países en cuyos Gobiernos coincidieron movimientos políticos afines, se plantea que no fue su posición política sino su apoyo a distintos paradigmas de regionalismo lo que inspiró la resistencia. Considerar el regionalismo brasileño como instrumento de política exterior que genera resistencia en su región y explorar esta última ayuda a comprender qué elementos pueden volverlo más aceptable para sus vecinos.

El objetivo es contestar los siguientes interrogantes: iqué resisten los Gobiernos sudamericanos que en algún momento no aceptan acciones o comportamientos de Brasil en Sudamérica: su poder material, su proyección global o su regionalismo? Si se observan cambios a lo largo de esa resistencia, ¿pueden estructurarse en etapas?, ¿qué las determina y por qué se dan?, ¿qué variables explicativas (factores) contribuyen a esa resistencia? y ¿cómo se 
vincula la resistencia sudamericana con paradigmas globales del regionalismo?

En la primera sección se presentan los estudios de caso para identificar los factores que explican la resistencia y sus etapas; en la segunda, se sistematizan y explican esos factores; en la última, se la vincula con interpretaciones globales del regionalismo. Los límites cronológicos son la primera cumbre presidencial sudamericana (2000), que inició una etapa proactiva del regionalismo brasileño (Flisfisch, 2011) y la administración de Dilma Rousseff (2010-2016), en la cual ese regionalismo perdió importancia relativa frente a la necesidad de contrarrestar la caída del crecimiento económico brasileño (Quenan, 2013). La naturaleza asimétrica y la centralidad de intereses brasileños en Mercosur no afectó a sus vecinos hasta que Brasil abandonó su política regional aislacionista para buscar el liderazgo regional (Flisfisch, 2011), enfatizando en una geopolítica sudamericana sobre la latinoamericana.

Como metodología para identificar estudios de caso, factores y etapas se recurrió a la revisión bibliográfica. También se incorporó el análisis del discurso gubernamental como técnica cualitativa (Sayago, 2014) para inferir las motivaciones de los Gobiernos de
Chile, Argentina y Venezuela que resistieron a Brasil y observar la vinculación de su resistencia con paradigmas globales del regionalismo.

\section{Estudios de caso y etapas de resistencia}

Como ejemplos de resistencia al regionalismo brasileño se seleccionaron tres: 1) en 2000-2003 Chile rechazó la presión brasileña para ingresar a Mercosur e inició negociaciones de un tratado de libre comercio con Estados Unidos; 2) en 2004 el Gobierno argentino de Néstor Kirchner se opuso a la creación de la Comunidad Sudamericana de Naciones (CSN), promovida por Brasil y establecida ese año, y 3) Venezuela apoyó su creación, pero al mismo tiempo estableció su propia organización regional (Alianza Bolivariana para los Pueblos de Nuestra América [ALBA] ${ }^{1}$.

En Chile, productores agrícolas e industriales se opusieron a entrar a Mercosur y prefirieron un acuerdo con Estados Unidos debido al tamaño de su mercado, ya que ese país era el segundo cliente de bienes agrícolas chilenos después de la Unión Europea (UE). Los industriales apoyaron la negociación para atraer inversión extranjera directa (IED), luego de que el

Ejemplos de resistencia fueron también esfuerzos de sus socios por aumentar el compromiso brasileño con Mercosur mediante la profundización de su institucionalización y la obstaculización de sus decisiones. El "poder suave" se manifestó en la oposición a que obtuviera un asiento permanente en el Consejo de Seguridad de Naciones Unidas (ONU) (Lapp, 2012). 
Gobierno garantizara que no firmaría un acuerdo con condiciones laborales o medioambientales (Manger, 2009, pp. 163-165, 171-174). El ingreso de Chile a Mercosur era difícil porque sus tarifas externas eran el doble de altas que las chilenas y el grupo había aprobado que toda futura negociación comercial de sus miembros debería hacerse de forma colectiva (Garrido, 2001, p. 46).

Además de razones pragmáticas, otras no económicas pesaron en la decisión chilena de iniciar negociaciones paralelas con economías desarrolladas. Los negociadores chilenos estaban conscientes de que las tarifas de Mercosur servían para proteger las exportaciones regionales de Brasil a expensas de sus socios, de manera que un acuerdo Chile-Mercosur significaba mayor beneficio para Brasil, a lo que se añadía que las exportaciones chilenas encontraban mayor demanda en economías extra-regionales.

Aunque los tratados comerciales pueden crearse para alcanzar objetivos políticos como disminuir tensiones vecinales, las relaciones Chile-Mercosur eran estables económica y políticamente. Una interpretación alternativa es que un país en desarrollo, si quiere aumentar la credibilidad de sus reformas económicas para atraer IED, gana más con un acuerdo de libre comercio con economías desarrolladas que con países en desarrollo (Schiff, 2002, p. 15). Hacia el 2000 las economías de Mercosur eran más volátiles que la chilena, la integración también aumenta- ba la posibilidad de que su volatilidad se contagiara a Chile y afectara su credibilidad internacional (Schiff, 2002, p. 35). José de Gregorio, ministro de economía chileno, agregaba otra motivación no estrictamente económica al declarar que Chile "no pensaba sacrificar" su "autonomía comercial" (Lapp, 2012, p. 152).

En el rechazo de Chile para ingresar a Mercosur el análisis se concentró en identificar la visión del Gobierno chileno acerca de Mercosur y Brasil y su apoyo a una estrategia de regionalismo abierto durante el Gobierno de la Concertación. Como esta incluía a izquierda y centro político chileno, su política exterior tenía rasgos de política de Estado y en ella las menciones a Mercosur y Brasil en el discurso oficial fueron positivas de forma constante, por lo que su apoyo al regionalismo tuvo mayor importancia. Según Van Klaveren (1998), el regionalismo abierto significaba que Chile podía negociar simultáneamente acuerdos con Mercosur y países desarrollados porque eran considerados complementarios. Si el primero bajaba sus aranceles, no era incompatible con el Área de Libre Comercio de las Américas (ALCA) ni con Chile-Estados Unidos (juego de suma variable, Flisfisch, 2011). Ingresar a Mercosur representaba terminar con la posibilidad de negociaciones simultáneas.

Chile buscaba la diversificación económica de sus mercados de exportación para disminuir su dependencia de un mercado externo único. Esta estrategia daba a Chile "autonomía decisional" y 
el acuerdo de asociación con Mercosur (firmado en 1996) era parte de esta. La diversificación implicaba que "una mayor cantidad de acuerdos, dispersa los niveles de dependencia y provee, en teoría, mayor autonomía para (des)hacerse de ellos" (González Ríos, 2014, p. 4). Esa autonomía no aisló a Chile de la región, ya que participó en Unasur, en el Foro del Pacifico (2007) y en la AP (2011), pero se basó en sus intereses nacionales (González Ríos, 2014, p. 25). Además, entre 1990 y 2004 el sector privado chileno invirtió en América Latina de forma que, para 2004, Chile era el tercer mayor inversionista en la región, después de Estados Unidos y la UE (Fuentes, 2006, p. 4).

Chile no se alejó de la región, pero se concentró en actividades a favor de la democracia y los derechos humanos (Cumbre del Grupo de Río, Carta Democrática Interamericana de la Organización de Estados Americanos, cláusulas democráticas en sus acuerdos de asociación) (Fuentes, 2006, p. 12). Berardi (2003) analiza los discursos del presidente Ricardo Lagos (2000-2003) acerca del acuerdo con Estados Unidos y muestra cómo el libre comercio se asocia con paz y democracia porque "un manejo sólido y responsable de nuestra economía [...] debería contribuir al aumento de la adhesión ciudadana a la democracia" (Lagos, 17 de agosto de 2001, citado en Berardi, 2003, p. 132).

La propuesta de incorporar a Chile al Mercosur surgió por relaciones personales entre los presidentes Lagos y
Fernando H. Cardoso (Brasil), desarrolladas durante el exilio del segundo en Chile. Según Marticorena (2000), esas relaciones llevaron a que el segundo propusiera un recorte de aranceles del Mercosur (que no llegó a formalizarse) para facilitar el ingreso chileno. Sin embargo, Mercosur proyectaba una imagen negativa porque en 1999 la crisis financiera internacional había provocado "una verdadera guerrilla de medidas proteccionistas y represalias" entre sus socios (Garrido, 2001, p. 74). Como trasfondo, también había fracasado la posibilidad de negociar la apertura agrícola en la OMC por problemas en Seattle, que el sector agrícola chileno interpretaba como el triunfo de la oposición de los países desarrollados a negociar subsidios agrícolas.

Si se combinan esas percepciones con las opiniones de empresarios chilenos que habían intentado utilizar el acuerdo de asociación Chile-Mercosur (1996) para exportar a Argentina, Brasil y Uruguay (Marticorena, 2000), puede percibirse una visión negativa de las oportunidades chilenas en Mercosur. Los empresarios indicaban que, aunque se habían rebajado aranceles, se los había sustituido por medidas paraarancelarias y burocráticas que no iban a desaparecer con el ingreso de Chile a Mercosur.

La preferencia de Chile por negociar acuerdos con países desarrollados frente a ingresar a Mercosur, más que mostrar voluntad de asilarse de Sudamérica, reconocía el riesgo que representaba para su desarrollo económico y 
político vincularse estrechamente con un acuerdo asimétrico que beneficiaba a Brasil. No rechazaba el poder de Brasil ni su proyección global, sino su regionalismo asimétrico, que excluía la posibilidad de otras negociaciones Comerciales. La búsqueda de un entorno democrático regional e internacional para su desarrollo chocaba con la percepción de Mercosur como acuerdo dominado por intereses de Brasil. Bajo esa política se mantuvieron Lagos y Michelle Bachelet, políticamente afines al Gobierno brasileño. En consecuencia, "[...] en vez de transformarse en un país 'periférico' en el marco del sistema regional cuyo 'eje' es Brasil, Chile logra constituir una plataforma [...] para alcanzar otros mercados [...] y [...] sigue apuntando a las exportaciones como motor del crecimiento" (Bianchini, 2004, s. p).

En 2004 no existía confianza política mutua entre el Gobierno peronista argentino y el Partido dos Trabalhadores (PT) brasileño (Granovsky, 2004), como mostró la oposición de Argentina a la reforma del Consejo de Seguridad de la $\mathrm{ONU}$, que promovía Brasil (Cárdenas, 2005; Diamint, 2005). Según Cisneros (2005, pp. 119 y 120), la decisión de crear la CSN era vista por Argentina como el fin de Mercosur porque otorgaba más poder a Brasil como pivote entre norte y sur de Sudamérica. La CSN contradecía intereses geopolíticos del Gobierno argentino, que buscaba evitar que su devaluación frente a Brasil después del default de 2001 aumentara en una organización regional mayor (Russell, 2006, p. 11) y seguir manteniendo su política de balance regional.

Finalmente, el Gobierno argentino suscribió el documento fundacional de la CSN sin la presencia de su presidente por dos factores: 1) el resurgimiento del tradicional sentimiento antiestadounidense del peronismo después del default y 2) la posición histórica de ese partido a favor de la integración regional. Aunque el regionalismo brasileño fue apoyado por factores relacionados con la política interna argentina, también fue resistido por factores de su política regional como el balance de poder. La continuación de esa política regional se observa en el discurso de Kirchner durante la visita de Lula da Silva a Buenos Aires (octubre 2003). Allí Kirchner mencionó a la CSN, pero incorporó a México -tradicional competidor de Brasil por el liderazgo regional- para destacar el carácter latinoamericano, no sudamericano, de la integración regional (Loza, 2005; Sindicato Mercosul, 2004).

El Gobierno de Kirchner en 2004 prefería profundizar y hacer más eficiente a Mercosur antes que invertir en la CSN. En medio de enfrentamientos Comerciales entre Argentina y Brasil, Kirchner destacó en la Cumbre de Ouro Preto (diciembre 2004) que, si bien el Mercosur "es nuestro bloque de pertenencia regional, los beneficios no pueden tener una sola dirección, [pues] ninguno de nuestros países es por sí mismo tan grande ni tan fuerte como para prescindir del destino regional" (Colombo, 2011, p. 163). 
También mantuvo su posición de balancear a Brasil al no apoyar su ingreso como miembro permanente del Consejo de Seguridad, con el argumento de que "Si Lula fuera el presidente por 50 años más, podría ser, pero, cómo no podemos tener certeza de ello, ¿Por qué Brasil va a representar a la Argentina? ¿Qué mérito tiene?" (Bielsa, citado en Elías, 2004).

Brasil era considerado actor clave, pero despertaba preocupación y dudas con respecto a su asimetría y posible hegemonía en Sudamérica, en especial por el estancamiento económico de Mercosur, que no se alteró con la estrategia de integración productiva ni la incorporación de aspectos sociales. Solo el nombramiento de Kirchner como secretario general de Unasur (2010) hizo que Argentina pareciera dispuesta a aceptar el horizonte sudamericano de integración que propiciaba Brasil (Russell y Tokatlian, 2011, pp. 11 y 12$)$.

Según Russell y Tokatlian (2011, pp. 13 y 14), en 2006 comienzan a influir factores como: 1) la mayor relevancia regional e internacional de Brasil, que lo convirtió en "país inevitable" o "indispensable"; 2) el "achicamiento" de la importancia económica y política argentina, y 3) la expansión de empresas brasileñas que generaban empleo y producción, pero mostraban debilidades del empresariado argentino. Para entonces, Argentina y Venezuela habían experimentado un acercamiento político, consolidado en el Gobierno de Fernández de Kirchner (2008-2016), que continuó la resistencia a Brasil al promover el ingreso de Venezuela a Mercosur.

Según Lapp (2012), la creación de ALBA paralelamente a la CSN es un ejemplo de búsqueda de poder fuerte (hard power) por parte de Venezuela para contrarrestar a Brasil. Aunque presentada como contrapropuesta al ALCA, ALBA competía con el proyecto brasileño utilizando recursos petroleros y financieros venezolanos durante el auge del precio internacional del petróleo (2003-2008). En Venezuela esa competencia se acompañó de la compra de armas y, según Flemes y Wojczewski (2011, p. 10), expresó su rechazo al regionalismo de Brasil. Con ALBA Venezuela forjó una red de influencia política en oposición a la brasileña, para la cual la integración regional debía hacerse mediante Mercosur ${ }^{2}$.

Aunque entre 2004 y 2007 Venezuela dio pasos para ingresar a Mercosur y fue miembro de la CSN, su discurso gubernamental fue contrario a la orientación económica del primero y no apoyó explícitamente a la CSN. Su prioridad era ALBA, como lo indica el título de un documento gubernamental venezolano en 2007 "ALBA: núcleo duro de la integración sudamericana"

Durante su visita a Caracas (agosto 2003), Lula da Silva no apoyó el ALBA, según el punto 3 de la declaración conjunta final (Giacalone, 2008). 
(Giacalone, 2013, p. 145). ALBA es un acuerdo regional venezolano donde el interés nacional se entiende como defensa y proyección del proyecto político gubernamental.

En Venezuela, a lo largo de 2005, el presidente Hugo Chávez objetó a la CSN y a Mercosur en varias oportunidades, y tanto este último como la Comunidad Andina (CAN) debían desaparecer (no converger en la CSN), porque eran maquinarias que no servían para enfrentar los retos sociales, políticos y económicos de la globalización (Venezuela, Ministerio de Relaciones Exteriores (MRE), 2006). Cuando en 2006 solicitó su ingreso a Mercosur, luego de salir de CAN y el Grupo de Los Tres (G-3), el Gobierno venezolano destacó la necesidad de "reformatearlo", considerando que su fin estaba próximo si no cambiaba su orientación (Reuters/EFE, 2006).

Esas declaraciones no entorpecieron el ingreso de Venezuela a Mercosur porque a Brasil el llamado venezolano a incorporar aspectos sociales le permitía posponer la profundización institucional del acuerdo, que proponía Argentina. Además, Brasil estaba interesado en los recursos petroleros venezolanos y su capacidad como mercado consumidor de productos brasileños durante el auge de los precios internacionales del petróleo.

El desacuerdo Brasil-Venezuela era con respecto al alcance de la CSN: articulación institucional y comercial para el primero y organismo político y de seguridad para el segundo (Giacalone, 2013, pp. 132 y 133). Ese alcance necesitaba contextos regionales distintos: Brasil buscaba paz y estabilidad en la región para expandir comercio, inversiones e infraestructura de transporte $y$ comunicaciones; Venezuela partía de la inevitabilidad del conflicto con Estados Unidos (Giacalone, 2008, p. 40). Resumiendo, Venezuela proponía una alianza defensiva en términos ideológicos, políticos y de seguridad, para contrarrestar la influencia regional estadounidense (Illera, 2005, p. 217), que chocaba con la visión regional de Brasil expresada en Mercosur y la CSN.

Cuando en 2008 la CSN se transformó en Unasur, la incorporación de propuestas venezolanas fue más discursiva que real porque el acuerdo no incluyó supranacionalidad, ni fuerza operativa o reconocimiento de la guerrilla colombiana como fuerza beligerante en el Consejo de Defensa Sudamericano (CDS) (Regueiro y Bárzaga, 2012; Quintanar, 2012). La resistencia al proyecto regional de Brasil se resume en Fundamentos de la Nueva Integración del Sur (2007), donde se declara que para "tomar el control" del proceso de integración "llevado por la Hermana República de Brasil bajo su tutela" (CSN) es necesario que Venezuela expanda el ALBA a toda América Latina y el Caribe (Giacalone, 2013, p. 144).

Los ejemplos de resistencia parecen desaparecer después de 2004. Una interpretación tentativa es, primero, que el auge exportador iniciado ese año generó optimismo e inclinó a los 
Gobiernos a aceptar el liderazgo brasileño mientras no interfiriera con su crecimiento económico. Segundo, las relaciones sudamericanas se trasladaron a la CSN-Unasur con una dinámica de oposición Brasil-Venezuela acompañada de declaraciones de cooperación y amistad. La oposición se manifestó en decisiones sectoriales (Banco del Sur, CDS, integración energética) (Quintanar, 2012). En todas ellas, las propuestas radicales venezolanas fueron derrotadas por otras más moderadas brasileñas, con apoyo de la mayoría de los Gobiernos sudamericanos. Esto sugiere que, desde 2004, cuando Venezuela impulsó una política regional radical ${ }^{3}$, fue considerada una amenaza por algunos Gobiernos sudamericanos que prefirieron apoyar a Brasil para controlarla ${ }^{4}$.

En tercer lugar, al comenzar la segunda década del siglo XXI, el fin del auge exportador aumentó la incertidumbre regional y el movimiento del comercio global del Océano Atlántico al Pacífico revalorizó la posición geográfica de Chile, Colombia, México y Perú. Sus gobiernos favorecían un regionalismo distinto del brasileño y, en 2011, concertaron sus resistencias individuales en la AP. Esta significó la reinserción económica de México en Sudamérica y el cuestionamiento de la existencia de un regionalismo sudamericano, auspiciado por Brasil (Flisfisch, 2011). Al mismo tiempo, la creación de la Comunidad de Estados Latinoamericanos y Caribeños (Celac), apoyada por México y vista con escepticismo por Brasil, representó la reinserción política mexicana en asuntos regionales. Celac fue apoyada por Argentina, Chile y Venezuela, que en algún momento resistieron a Brasil y, aunque es vista como reacción a la influencia estadounidense, es más amplia que las organizaciones sudamericanas y restablece un horizonte latinoamericano para la integración regional.

Desde 2011 la resistencia al regionalismo brasileño promovió instituciones regionales (AP, Celac), mientras Brasil experimentaba el debilitamiento de su economía (Quenan, 2013) y dejaba de necesitar a Sudamérica como plataforma de proyección global (Pinheiro y Gaio, 2014). En paralelo, en Venezuela las protestas políticas internas y el fin del auge petrolero debilitaban su percepción como amenaza regional. Otro cambio fue que para entonces Sudamérica no atraía el mismo interés de actores extrarregionales (Estados Unidos, UE, China) que diez años antes.

3 En 2004 Venezuela diseñó una estructura de apoyo (Telesur, Petrocaribe, Banco del ALBA) para difundir su política regional y el ALBA (Fermín, 2009, pp, 346 y 347).

$4 \quad$ La amenaza del ALBA hizo que Chile promoviera el Artículo 13 del tratado constitutivo de Unasur, que establece que la adopción de una decisión por consenso no obliga a aplicarla, de manera que "posibilita a una minoría, que puede consistir de uno solo, evitar costos o perjuicios inaceptables a sus principios o intereses [...]" (Flisfisch, 2011, p. 133).

5 Bolivia resistió a Brasil en 2006, cuando con apoyo venezolano nacionalizó el gas y afectó los intereses de la empresa estatal brasileña Petrobras. 
En esa coyuntura, Chile se asoció con Gobiernos que comparten similares políticas económicas y orientación política y apoyan el regionalismo abierto frente al regionalismo antiestadounidense de Brasil. Con la AP y la Celac se inició una etapa de resistencia concertada en la que varios países combinan sus esfuerzos.

\section{Factores de resistencia}

Los factores observados en los estudios de caso pueden diferenciarse en sistémicos (afectan a toda una región o sistema, como Sudamérica), normativos (relacionados con un modelo ideal de comportamiento o considerados normales en términos culturales) y externos (presencia de actores extrarregionales poderosos que buscan acuerdos con otros países sudamericanos).

Los sistémicos son bajo nivel de interdependencia económica y tendencia histórica a mantener instituciones regionales incompletas, que representan intereses nacionales antes que de la región. Con respecto al primero, según Gudynas (2000), Mercosur, del cual Brasil es eje político y económi$\mathrm{co}$, representa una sumatoria de economías exportadoras extrarregionales con poca integración económica entre ellas. Gobierno y empresas brasileñas negocian directamente su inserción en la economía global porque no necesitan de Mercosur para competir. Mercosur no se estableció con ese fin, sino para asegurar el control brasileño en mercados regionales y representar a la región en foros internacionales.

Brasil mantiene en Mercosur estructuras regionales proteccionistas que apoyan la internacionalización de sus empresas y producen choques con sus socios. En el 2000, las cadenas de valor agroindustriales brasileñas eran nacionales y en soja, cereales y carne competían internacionalmente con las de Argentina, Uruguay y Paraguay (Bisang y Gutman, 2000). La situación no había cambiado para 2013, pero se había profundizado durante el auge exportador de productos básicos (Paolino, 2014, p. 83; O'Connor, 2010, p. 58). La integración productiva, impulsada por Mercosur en la primera década del siglo XXI, creó cadenas de valor en sectores poco importantes, mientras Brasil no importaba de la región sino una pequeña parte de insumos y repuestos de los bienes que le exportaba; el resto se originaba en su mercado doméstico o proveedores extrarregionales.

Los beneficios económicos del regionalismo para Brasil explican por qué su Gobierno promueve políticas comerciales distintas en la OMC y Mercosur. Mientras en las negociaciones agrícolas multilaterales promueve el libre comercio, mantiene una visión cerrada de su región. Esto se observa en la negociación del ALCA. Aunque la autonomía política frente a Estados Unidos se considera la motivación brasileña, el fracaso de esa negociación en 2005 consolidó a Brasil como un importante proveedor de bienes y servicios en la región, protegido por las tarifas prefe- 
renciales de Mercosur y los acuerdos de asociación con otros países sudamericanos. Como resultado, entre 2002 y 2011, las exportaciones brasileñas a Sudamérica pasaron de US 7,4 a 45,2 billones de dólares y la región absorbió más productos manufactureros de Brasil que el resto del mundo (Pinheiro y Gaio, 2014, p. 16). Al finalizar el auge exportador, era obvio que Mercosur resultaba positivo para Brasil, pero no tanto para sus socios, porque en 2010 Brasil atraía menos bienes de ellos que en 2000 y había aumentado la asimetría material y política con sus vecinos (Durani, 2011, p. 13; Souza, Oliveira y Gonçalvez, 2010, p. 21).

El segundo factor sistémico surge de observaciones de Malamud (2016b) sobre el carácter fragmentado de la experiencia geográfica e histórica regional bajo la dominación colonial, que la dividió en una pluralidad de situaciones económicas y políticas orientadas hacia el exterior y con pocos vínculos entre ellas. Esa tendencia se afirmó con la independencia, cuando los Estados nacionales buscaron establecer su poder y control territorial. Guerras civiles, revueltas y proyectos de modernidad fracasaron luego de empujar las expectativas de la sociedad en direcciones opuestas. En el siglo XX la inserción internacional económica y política de las naciones mayores (Argentina, Brasil, México) añadió tensión a un proceso que, cuando terminó en los años 30, dejó a los Gobiernos latinoamericanas entregados a proyectos nacionales de desarrollo, que confirmaron la tendencia histórica.
En la segunda mitad del siglo XX, una coyuntura externa de integración europea, descolonización en Naciones Unidas (ONU) y Guerra Fría fomentó el interés por el desarrollo económico y la integración. Se construyeron instituciones regionales para fomentar el desarrollo económico como la Asociación Latinoamericana de Libre Comercio (ALALC, 1960)-desde 1980 Asociación Latinoamericana de Integración (ALADI)-, el Pacto Andino y el Mercado Común Centroamericano. La dimensión regional siguió siendo el horizonte, porque ninguna abarcó a toda la región y las decisiones respondieron a intereses de los países más grandes en cada una de ellas. Así la motivación de Bolivia, Chile, Colombia, Perú (luego Venezuela) para establecer el Pacto Andino (hoy CAN) fue su desacuerdo con el carácter desequilibrado de los logros económicos de ALALC a favor de Argentina, Brasil y México. En los años 90, el Pacto Andino abandonó objetivos iniciales como la planificación industrial, para acomodar la restructuración económica de sus economías mayores (Colombia, Perú, Venezuela).

Para fines del siglo XX, habían surgido nuevos grupos regionales -el G-3 (Colombia, México, Venezuela) y la Asociación de Estados del Caribe (AEC)-. Cada uno se anunciaba como faro para guiar la integración regional, pero era plataforma de proyección política para distintos Gobiernos nacionales -Mercosur sirvió para la proyección regional de Brasil y Argentina en el Cono Sur y el G-3 y la AEC, para 
la de Colombia, México y Venezuela en Centroamérica y el Caribe-.

A principios del siglo XXI el regionalismo se aceleró con la presencia de Gobiernos populistas de izquierda en Argentina, Brasil y Venezuela. Como resultado, las negociaciones CANMercosur para crear un área de libre comercio y unificar sus secretariados terminaron por establecer la CSN (2004) y Unasur (2008), instituciones que representan intereses políticos brasileños. Ese proceso fue paralelo al desarrollo de ALBA, instrumento de poder regional de Venezuela, y la reacción de otros Gobiernos al regionalismo de la izquierda populista generó la AP en 2011, como derivación del Foro del Pacifico (2007).

Las declaraciones de solidaridad y cooperación no ocultan la continuación de la tendencia a construir esferas de influencia nacional antes que instituciones representativas de intereses regionales. Esa tendencia histórica a mantener instituciones regionales incompletas -ya sea porque no logran alcanzar sus objetivos o implementar decisiones o porque su alcance geográfico es reducido-convierte a las instituciones regionales en instrumentos para que Gobiernos con diferentes niveles de poder construyan alianzas políticas. Adicionalmente, reduce la necesidad de aceptar el regionalismo brasileño y explica también el confuso panorama de la integración latinoamericana.

La ampliación de Mercosur con Venezuela (2012) y Bolivia (2014) -promo- vida por los gobiernos populistas de Lula (2003-2011) y Rousseff (Brasil) y Néstor y Cristina Kirchner (Argentina) - y la reacción posterior contraria de los Gobiernos de Michel Temer y Mauricio Macri en 2016 confirman que Brasil y Argentina consideran a Mercosur un instrumento de sus respectivas políticas regionales. Por ello, no están dispuestos a dejar ingresar a Gobiernos cuyos objetivos son distintos de los suyos. Se la interpreta como resultado de cambios de orientación política en sus gobiernos, pero esos cambios determinan que otros países se incluyen o rechazan en Mercosur sin alterar su rol como instrumento de política exterior.

Venezuela y Bolivia tampoco abandonaron ALBA al ingresar a Mercosur porque ALBA les permite proyectar en sus ámbitos domésticos la imagen de que sus Gobiernos cuentan con apoyo regional. Esa legitimidad externa es importante cuando la escena doméstica es frágil, los Gobiernos enfrentan oposiciones internas fuertes y necesitan mejorar sus imágenes nacionales (Cascante, 2014, pp. 38-42). Mantener instituciones regionales incompletas hace que Gobiernos con diferentes niveles de poder construyan redes de apoyo y las presenten a sus audiencias domésticas como ejemplo de que son actores regionales influyentes. También otorga poder de veto en organizaciones mayores cuyas decisiones son consensuadas (Unasur) (Álvarez y Beirute, 2010; Flisifisch, 2011), lo que les permite resistir al regionalismo brasileño. 
En cuanto a factores normativos, en muchos países sudamericanos prevalece un sentimiento de excepcionalidad y el rechazo a abandonar soberanía y autonomía de acción por la injerencia de vecinos mayores. El primer factor se relaciona con el lugar de la región en la inserción internacional de las naciones sudamericanas. El desarrollismo de la segunda mitad del siglo XX implicó una identificación latinoamericana positiva para Argentina y Brasil, pero esa identidad fue matizada por la percepción de su excepcionalidad (Merke, 2008). Esta se mantiene porque la mayor parte de sus ciudadanos no se considera todavía latinoamericana o sudamericana (Onuki, Mouron y Urdinez, 2016).

La excepcionalidad de Brasil nació de su aislamiento histórico de la región desde la época colonial y su sentido de autonomía nacional. Aunque esta se destaca en relación con Estados Unidos, es relevante para entender por qué Brasil rehúye pagar el costo de convertirse en poder regional e institucionalizar Mercosur. Malamud (2016a) lo explica por el interés brasileño en reservar recursos propios para su desarrollo y proyección global, pero esa actitud contribuye a la resistencia de sus vecinos. Si el regionalismo implica pérdida de soberanía, esta puede compensarse con las ganancias económicas que se obtengan, pero la excepcionalidad impide a Brasil compartir beneficios económicos con sus socios y contribuye a que ellos defiendan su propia soberanía.
El segundo factor normativo (reticencia a abandonar soberanía y rechazo a injerencia de vecinos poderosos) (Serbin, 2010, 6) forma parte de la tradición latinoamericana. Esto limita la aceptación del poder regional (Serbin, 2010) y los acuerdos que este promueve (Serbin, 2013, p. 47). La afinidad ideológica de Gobiernos populistas de izquierda en la primera década del siglo XXI no alteró esa característica. La Unasur, apoyada por todos ellos, muestra diferencias entre Brasil y Venezuela acerca de la dimensión de la región y sus objetivos prioritarios (Giaconeli, 2008; Serbin 2010; Quintanar, 2012).

Esa tradición se expresa en la preferencia de los Gobiernos sudamericanos por organizaciones regionales interestatales, donde cada país tiene un voto, las decisiones son consensuadas y su implementación, voluntaria (Flisfisch, 2011). El mismo Brasil enfatiza la soberanía nacional sobre los acuerdos regionales, ya que desde principios del siglo XX su constitución y política exterior apoyan elaboraciones conceptuales de derecho internacional que favorecen la soberanía (Doctrina Calvo, 1868; Principio Drago, 1902) (Almeida, 2013).

El concepto de autonomía, nacido en la Guerra Fría, ha cambiado desde los años 70 (Bernal-Meza, 2013), pero sigue siendo relevante en las políticas exteriores sudamericanas. En la brasileña se expresa en su negativa a profundizar la institucionalización de Mercosur para no perder libertad de acción glo- 
bal y regional. Aunque la conformación inicial de Mercosur sigue principios del regionalismo abierto, la necesidad de Lula da Silva de contentar al ala radical del PT mientras continuaba políticas macroeconómicas liberales de Gobiernos previos (Ribeiro, 2014, pp. 114 y 115) promovió un discurso de política exterior que exaltó su autonomía frente a Estados Unidos. Esa narrativa para el imaginario doméstico contribuyó a que vecinos sudamericanos, que no comparten la noción de una autonomía regional antiestadounidense, resistieran a Brasil.

Llenderrozas (2013, p. 131) ha señalado la existencia de más de un paradigma normativo regional en la Celac. Esta incluye principios heredados de la tradición legal europea (westfaliana) sobre igualitarismo soberano de los Estados, no intervención (autonomía) e integridad territorial -que conspiran contra la integración (Llenderrozas, 2013, p. 147)- junto con otros que enfatizan democracia, derechos humanos y desarrollo económico. Esto se debe a que la región es un sistema abierto con un grado alto de europeización y americanización en el que influyen ideas de la Revolución francesa y estadounidense (libertad, igualdad, entre otros) desde sus procesos de independencia.

Si los principios del primer paradigma exigen decisiones unánimes y participación voluntaria, que apoyan la resistencia al regionalismo brasileño, los segundos hacen que algunos temas justifiquen la actuación regional (cláusulas democráticas de CAN, Mercosur, Unasur). Ambos influyen sobre los acuerdos regionales, pero hay mayor consenso normativo acerca de los primeros que de los segundos. Esto explica que la AP condicione el ingreso de nuevos miembros al respeto de la democracia y el Estado de derecho, mientras el ALBA se opone a la aplicación de cláusulas democráticas a Venezuela.

Durante la formación del Estado-nación latinoamericano la alianza brasileña con Estados Unidos y la argentina con Gran Bretaña fueron manifestaciones de la presencia de actores extrarregionales poderosos interesados en la región (Merke, 2008). Con el fin de la Guerra Fría los Gobiernos latinoamericanos debieron reacomodar sus políticas exteriores y relaciones con esos actores. Sin embargo, se mantiene la tendencia a establecer formas preferenciales de asociación económica o política con alguno de ellos. También es común que vecinos que no comparten similares dotaciones de factores con otros mayores encuentren menos atractiva la integración con ellos (Tovías, 2008). Como la racionalidad económica para que un país pequeño firme un acuerdo comercial con un país lejano es menor frente a hacerlo con uno cercano, deben existir razones políticas. Entre ellas, Tovías (2008, pp. $15-17,19)$ destaca que los acuerdos preferenciales con socios comerciales "naturales" hacen a las naciones pequeñas más dependientes de vecinos grandes, mientras los extrarregionales disminuyen esa dependencia. 
A finales del siglo $X X$ y principios del XXI hubo amplia oferta de actores extrarregionales interesados en relaciones preferenciales con naciones sudamericanas. Estados Unidos y la UE buscaron acuerdos empujados por el optimismo neoliberal luego de la caída de la Unión Soviética y el tratado de Maastricht (1992), respectivamente. Las ofertas predominaron hasta la crisis de 2008, aunque los sucesos de 2001 ya habían disminuido el interés estadounidense. Ambos actores firmaron acuerdos estratégicos con Brasil, pero también buscaron sus propios intereses económicos y políticos en acuerdos con otras naciones sudamericanas. El interregionalismo europeo fue usado para atraer a naciones sudamericanas a firmar acuerdos de asociación con la $U E$, que incluían comercio preferencial, iban acompañados de condicionalidades sobre democracia y derechos humanos, y buscaban fortalecer la integración regional. Sin embargo, los acuerdos no fueron birregionales, sino con naciones individuales (Chile, Colombia, Perú y Ecuador) y les permitieron resistirse al regionalismo brasileño.

Un actor externo nuevo fue China, que había experimentado una restructuración económica que culminó en 2000 con su ingreso a la OMC. Su interés por materias primas, alimentos y energía la acercó a América Latina (Heilmann y Schmidt, 2014, pp. 33 y 34). Aunque firmó acuerdos comerciales con México y Chile, fueron sus compras de productos básicos latinoamericanos a precios altos las que produjeron el auge exportador 20032008 y contribuyeron a que otras na- ciones sudamericanas no se plegaran al regionalismo brasileño.

Brasil participó del auge y, en el proceso, aumentó su dependencia del mercado global y disminuyó su integración con mercados regionales. Aunque Brasil y China enfatizaron una agenda sursur, esta es más costosa para Brasil que no puede suscribir el costo de la acción colectiva regional y es afectado por importaciones industriales chinas a mercados latinoamericanos (Hirst, 2009, p. 128). Más comercio chino con Argentina promueve intereses comunes en Mercosur, pero crea competencia entre sus miembros para atraer IED de ese origen (Hirst, 2009, pp. 132 y 133).

La presencia china se interpreta como una manera de otorgar mayor autonomía regional frente a Estados Unidos, pero el triángulo Estados Unidos-China-América Latina no existe en el vacío. Las mayores exportaciones chinas van a Estados Unidos y UE, y provienen de compañías multinacionales, mientras que insumos y materias primas se originan en América Latina, África y Asia (Stallings, 2009). Cualquier elemento que rompe el ciclo (como la crisis de 2008 en los países desarrollados) disminuye el crecimiento de exportaciones e importaciones chinas, influye en su política económica y afecta a clientes y proveedores, como lo demuestran los años posteriores a 2011.

En el caso chileno, los factores que incidieron fueron poca interdependencia económica entre Chile y Mercosur para ciertos sectores, protección de la autonomía de acción chilena y 
el hecho de que Estados Unidos y la UE estaban interesados en acuerdos preferenciales con ese país (o sea factores de los tres tipos). En el argentino, elementos normativos (regionales y domésticos) predominaron tanto en la resistencia, como en la aceptación formal de la CSN.

En Venezuela, aunque aumentaron las relaciones comerciales VenezuelaMercosur, había poca interdependencia económica con Brasil (factor sistémico). El cambio de orientación política del Gobierno venezolano se acompañó de un cambio del paradigma regionalista hacia uno contrario al regionalismo abierto y la economía de mercado. Aunque el discurso político de izquierda exaltó a Brasil como eje de un regionalismo autosuficiente y estatista, contrario al imperialismo, a Estados Unidos y a la globalización, tuvo "poco anclaje en la realidad" (Flisfisch, 2011, p. 122); y creó divergencias concretas con Venezuela en Unasur.

La Tabla 1 resume etapas de la resistencia sudamericana y factores que influyeron en los estudios de caso.

Tabla 1. Etapas y factores en estudios de caso

\begin{tabular}{|l|l|l|l|}
\hline \multicolumn{1}{|c|}{ Factores y etapas } & \multicolumn{1}{c|}{ Sistémicos } & \multicolumn{1}{c|}{ Normativos } & \multicolumn{1}{c|}{ Externos } \\
\hline $\begin{array}{l}\text { Resistencia individual } \\
\text { abierta (2000-2004) }\end{array}$ & $\begin{array}{l}\text { Casos Chile/Mercosur } \\
\text { y Venezuela/CSN }\end{array}$ & $\begin{array}{l}\text { Casos Argentina/CSN y } \\
\text { Chile/Mercosur }\end{array}$ & Caso Chile/Mercosur \\
\hline $\begin{array}{l}\text { Resistencia moderada en } \\
\text { Unasur (2005-2010) }\end{array}$ & $\begin{array}{l}\text { Optimismo económico } \\
\text { por auge exportador }\end{array}$ & $\begin{array}{l}\text { Percepción de amenaza } \\
\text { política regional } \\
\text { (Venezuela) }\end{array}$ & $\begin{array}{l}\text { Interés económico de } \\
\text { actores externos (hasta } \\
\text { 2008) }\end{array}$ \\
\hline $\begin{array}{l}\text { Resistencia concertada } \\
(2011-2013)\end{array}$ & $\begin{array}{l}\text { Creación de Alianza del } \\
\text { Pacífico }\end{array}$ & $\begin{array}{l}\text { Creación de Celac y } \\
\text { Alianza del Pacífico }\end{array}$ & $\begin{array}{l}\text { Creación de Alianza del } \\
\text { Pacífico }\end{array}$ \\
\hline
\end{tabular}

Fuente: elaboración propia.

\section{Conclusiones}

Desde principios del siglo XXI, mientras Brasil expandía su regionalismo, Chile, Argentina y Venezuela lo resistieron, pero posiciones divergentes con respecto a paradigmas regionalistas impidieron que concertaran sus resistencias. En el caso chileno queda claro su apego al regionalismo abierto. El regionalismo argentino también buscó reinsertar a Argentina en el mundo, pero su énfasis en el mercado interno y el Estado conspiró para que su diversificación expor- tadora se limitara a cooperar con Brasil en negociaciones en la OMC y el ALCA (Colombo, 2011). Esto no evitó que discreparan acerca de la CSN-Unasur y acumulación de poder regional para Brasil (Bernal-Meza, 2008). Entre el ALCA y la propuesta sudamericana de Brasil, según Bernal-Meza (2008), Kirchner se inclinó por la segunda, pero el discurso presidencial que cita no menciona a la CSN/Unasur, sino a la prioridad que tienen la "profundización de MERCOSUR y la relación con los países asociados, Chile y Bolivia [...]" (p. 165). 
En cuanto al ALBA, Briceño Ruiz (2010) se pregunta si existe compatibilidad entre ella y Mercosur y concluye que, aunque Mercosur ha cambiado y adoptado un modelo híbrido que combina lo comercial y lo social, es escasa la capacidad de incidencia venezolana para transformarlo. La visión regionalista de Venezuela no facilita su acercamiento a Chile o a Argentina, pero su resistencia al regionalismo brasileño subyace a declaraciones de cooperación y solidaridad con Brasil en el periodo analizado.

Mientras tanto, la proyección regional venezolana posterior a 2004 definió líneas de resistencia a ella, primero, en el apoyo a Brasil dentro de Unasur y, luego, en la AP. En 2014 esta última asumió una posición cooperativa hacia Brasil al proponer la "convergencia en la diversidad" AP-Mercosur (Da Silva y Lagos, 2014), que reconoce que esos acuerdos no representan principios económicos opuestos. Luego de cambios de orientación política en Argentina y Brasil (2015-2016) puede considerarse expresión concertada de resistencia al ALBA, el único acuerdo latinoamericano marginado de la convergencia.

En un contexto sudamericano donde hay mucho voluntarismo político y poca interdependencia económica (González y Velázquez, 2013), la resistencia se expresa en distintas estrategias: 1) en Chile, mediante la firma de acuerdos comerciales con actores extrarregionales, a la que luego se agrega la creación de una nueva organización regional (AP) con Gobiernos afines; 2) en Argentina, poca cooperación con objetivos geopolíticos brasileños y, más tarde, alianza con otro actor regional (Venezuela) que resiste a Brasil, y 3) en Venezuela, a través de la creación de otra organización regional (ALBA) y el posterior ingreso a Mercosur de Venezuela y otro miembro del ALBA (Bo(ivia) ${ }^{5}$ para influir desde adentro. Las estrategias cambian, pero su sentido de resistencia individual abierta, moderada o concertada con otros se mantiene.

Si se relaciona la resistencia con interpretaciones globales del regionalismo, se encuentran dos enfoques opuestos. Para Buzan (2004) y Acharya (2014, pp. 85 y 86), la existencia de economías emergentes que son poderes regionales originará un sistema internacional región-céntrico. En él, las regiones sustituirán a las naciones-Estado como actores del sistema internacional, los poderes regionales permanecerán enraizados en sus regiones y las reorganizarán bajo un patrón de influencia eje-rayos. Las regiones estarían relativamente aisladas de influencias globales y este "multilateralismo regional" traería paz y estabilidad al sistema global, si Estados Unidos disminuye su hegemonía y el multilateralismo no logra controlar problemas comunes (Mylonas y Yorulmazlar, 2012).

Pero, según Garzón (2015), el mundo multipolar generará fuerzas centrífugas en las regiones (multipolaridad descentralizada0). En ella, los lazos económicos y políticos no van a converger en poderes regionales, sino a trascender la región por la emergencia de nue- 
vos polos de poder extrarregionales y la tendencia de naciones pequeñas a minimizar el costo de acceder a recursos externos (mercados, inversiones, tecnología) y mantener su autonomía política. Esto es visible porque poderes regionales como Brasil, China e India han desarrollado intereses extrarregionales en África y entre los países africanos ha aumentado la tendencia a responder positivamente a esos actores sin abandonar lazos regionales.

Las políticas exteriores de naciones emergentes muestran el predominio de intereses nacionales que solo ocasionalmente se posponen por consideraciones geopolíticas o geoeconómicas. Aunque se presentan como intermediarios entre poderes centrales y naciones de menor poder relativo, esa función no es vista con ojos positivos por sus vecinos que consideran que los poderes regionales buscan alcanzar protagonismo global y no solucionar problemas regionales (Vieira y Alden, 2011). Hveem (2000, p. 71) lo sintetiza diciendo que en la Posguerra Fría el regionalismo pasó de estrategia para maximizar la capacidad económico-política de una región a ser instrumento de legitimidad política y construcción de identidad para poderes regionales.

En Sudamérica, se manifiesta en que Brasil se ha convertido en proveedor regional grande y no en plataforma para transformar insumos regionales en bienes finales de exportación (lapadre y Tajoli, 2014, pp. 95-97). De esta forma, otros países sudamericanos eran más dependientes de Brasil en 2000 que en 2010 y el índice de globalización brasileño no es mayor que el de sus vecinos (Chen y De Lombaerde, 2014, pp. 123 y 124).

El regionalismo brasileño nació en una coyuntura internacional y un ambiente intelectual dominados por el multilateralismo regional y Brasil construyó estructuras sucesivas para posicionarse como elemento clave para el desarrollo económico y la estabilidad política sudamericana. Mientras tanto, Chile en sus negociaciones se acerca al paradigma de la multipolaridad descentralizada. Factores materiales (tamaño de mercados domésticos, recursos naturales, ubicación geográfica, entre otros) e historia de sus respectivos desarrollos económicos y políticos explican las preferencias de sus gobiernos ${ }^{6}$.

Distintos factores limitaron la aceptación del regionalismo de Brasil por naciones vecinas, estableciendo diferentes formas de resistencia. Si disparidades de poder limitan a esas naciones, también crean rechazo en sus relaciones intrarregionales. Razones políticas domésticas y razones económicas externas permitieron a Chile construir poder mediante acuerdos con actores extrarregionales para

Argentina y Venezuela pueden beneficiarse de una multipolaridad descentralizada, pero factores políticos domésticos lo impidieron entre 2000 y 2013. 
resistir a Brasil entre 2000 y 2003. Por razones normativas, Argentina respondió al regionalismo brasileño con medidas para limitarlo en la CSN, pero otras razones normativas internas le impidieron mantener su resistencia. Bajo la administración de Cristina Kirchner, Argentina como aliada de Venezuela (Battaleme, 2014) mostró una conducta ambivalente frente a Brasil, destacada por Russell y Tokatlian.

En conclusión, sus vecinos sudamericanos no resistieron el poder material de Brasil (que existía antes de 2000 y ninguno de ellos puede igualar) ni su proyección global (Miranda, 2017, confirma la "soledad política" de Argentina en el G20), sino la forma como Brasil usó su poder para organizar la región en su beneficio. El hecho de que los Gobiernos que lo resistieron, excepto Argentina, desarrollaran organizaciones regionales refuerza la noción de que su resistencia es al regionalismo brasileño y no a su poder o proyección global.

Flemes y Wehner (2012) consideran factores sistémicos a los derivados de la posición de Brasil y sus vecinos en un sistema jerárquico (poder regional, poderes secundarios) que imita el sistema internacional. La posición jerárquica otorga a los actores secunda- rios capacidades similares que utilizan para balancear al poder mayor, pero en Sudamérica ellos emplean estrategias distintas. Para esos autores esto está determinado por factores domésticos propios de cada poder secundario, que adquieren mayor influencia en política exterior en periodos de paz y estabilidad. Su marco de análisis es neorrealista y en él "[...] if a region consists of one primary and more than one secondary power, the relative systemic positions of the secondary powers do not deviate considerably from each other and..., can be excluded as an explanatory factor for the variation in $[\ldots]$ strategies" ${ }^{\prime \prime}$ (Flemes y Wehner, 2012, p. 6). Estos autores asumen que la fuerza que moldea esas estrategias es la influencia del sistema internacional porque la región forma parte de este.

Pero en nuestra interpretación la resistencia a Brasil se apoya en factores sistémicos sudamericanos surgidos de su experiencia histórica ${ }^{8}$ : bajo nivel de interdependencia económica entre Brasil y sus vecinos, y acuerdos regionales que expresan intereses nacionales de los Gobiernos que los promueven, junto con conceptos de soberanía, autonomía y no injerencia enraizados en la región (factores normativos) y presencia de actores extra-

\footnotetext{
"[...] si una región tiene más de un poder secundario, las posiciones sistémicas relativas de los poderes secundarios no se desvían considerablemente una de otras... y pueden excluirse como factores explicativos de las variaciones en [...] estrategias" (traducción propia.)

8 Flemes y Wehner $(2012$, p. 7) no incluyen motivaciones históricas en su análisis porque para el neorrealismo las únicas motivaciones de ese tipo son experiencias previas de rivalidad o conflicto, que no encuentran en la relación Brasil-Sudamérica.
} 
rregionales interesados en relaciones preferenciales con países sudamericanos (factores externos).

Esto sugiere un nivel de análisis de la política exterior y el regionalismo latinoamericanos en lo que Battaleme (2014, p. 5) llama la doble periferia -un contexto regional donde los Gobiernos están sometidos a un poder que declina, pero todavía es fuerte (Estados Unidos) y a otro que asciende, pero no consigue imponer su control (Brasil)-. Indirectamente, cuestiona un marco de análisis neorrealista que no incorpora elementos de la tradición histórica y normativa regional. En cuanto al análisis del discurso como metodología, este se nutrió de aportes publicados y declaraciones en la prensa y documentos oficiales. La revisión no pretendió ser exhaustiva, sino destacar la vinculación entre resistencia, factores sistémicos regionales y paradigmas globales del regionalismo, una vinculación que necesita ser profundizada en otros estudios.

En la primera década del siglo XXI aumentó la capacidad de agencia (autonomía relativa) de los Gobiernos sudamericanos en una coyuntura global permisiva, que surgió del fin de la Guerra Fría, los eventos del 11 de septiembre 2001 y la emergencia de un mundo multipolar, mientras al nivel regional el crecimiento económico (auge exportador) otorgaba más recursos para ejercitarla. La etapa proactiva del regionalismo brasileño y la resistencia de sus vecinos pueden asociarse con esa capacidad aumentada, que tam- bién amplía la inestabilidad en contextos geopolíticos regionales (Hunter, 2001). Sin embargo, condiciones similares en otras regiones, como el sudeste asiático, muestran no solo resultados diferentes, sino también la existencia de factores sistémicos distintos, como mayor interdependencia económica en torno a China (Beeson, 2010).

La resistencia en Sudamérica varía en los estudios de caso y en el mismo país a lo largo de los años, pero existe un factor común: la continuación de la tendencia histórica a construir organizaciones regionales o alianzas políticas para desarrollar esferas de influencia nacional, en lugar de instituciones para solucionar problemas regionales. Esfuerzos por establecer cooperación económica y política entre esas alianzas, como la convergencia Mercosur-AP, pueden contribuir a cambiar esa situación.

En un contexto global donde el escenario del multilateralismo regional pierde énfasis por problemas de la UE, mientras la reorientación económica china y un Gobierno proteccionista en Estados Unidos afectan a economías emergentes como la brasileña, la convergencia puede iniciar una nueva etapa del regionalismo latinoamericano. El fin del boom exportador y una sucesión de cambios políticos hacen crecer el sentimiento de incertidumbre y el establecimiento de vínculos entre acuerdos regionales puede promover la articulación regional en una geopolítica y geoeconomía global cambiante. 
Mirar al regionalismo como instrumento de política exterior, que genera resistencia, contribuye a comprender qué elementos pueden hacerlo aceptable y a identificar estrategias que permitan navegar el nuevo contexto global. De esta forma, la resistencia tiene implicaciones para la integración regional latinoamericano, que es necesario comprender y profundizar, si se quiere que el proceso sea menos resistido por sus participantes.

\section{Referencias}

Acharya, A. (2014). Global international relations and regional worlds. International Studies Quarterly, 58(4), 647-659. Recuperado de http://on$\underline{\text { linelibrary.wiley.com/doi/10.1111/ }}$ isqu. 12171

Almeida, P.D. de. (2013). Sovereignty and regional integration in Latin America. Contexto Internacional, 35(2), 471-495. Recuperado de http://www.scielo.br/pdf/cint/ v35n2/a06v35n2.pdf

Álvarez, A. y Beirute, T. (2010). La integración latinoamericana y caribeña desde sus subregiones. Facultad Latinoamericana de Ciencias Sociales [Flacso], Corporación Andina de Fomento [CAF]. Recuperado de https://www.scribd.com/ document/79061411/Integraciondesde-Subregiones

Battaleme, J. (2014). Realismo periférico y doble periferias. Buenos Aires: International
Studies Association [ISA], Facultad Latinoamericana de Ciencias Sociales [Flacso].

Beeson, M. (2010). Asymmetrical regionalism: China, Southeast Asia and uneven development. East Asia, 27, 329-343.

Berardi, L. (2003). El tratado de libre comercio (TLC) con EE.UU. en el discurso del Presidente Ricardo Lagos. En L. Berardi, (Ed.), Análisis crítico del discurso (pp. 125-143). Santiago de Chile: Frasis. Recuperado de https://www.researchgate. net/publication/303920157

Bernal-Meza, R. (2008). Argentina y Brasil en la política internacional. Revista Brasileira de Politica Internacional, 51(2), 154-178. Recuperado de http://www.scielo.br/pdf/ rbpi/v51n2/v51n2a10.pdf

Bernal-Meza, R. (2013). Las relaciones China-Mercosury Chile. Ciclos en la Historia, la Economía y la Sociedad, 21(42). Recuperado de http://scielo.org.ar/scielo.php?script $=$ sci a rttext\&pid =S 1851 $\underline{37352013000200004 \& \operatorname{lng}=\mathrm{es} \& \mathrm{n}}$ $\underline{\mathrm{rm}=\mathrm{iso}}$

Bianchini, M. C. (2004). Chile y el Mercosur: visiones diferentes del futuro de la integración. Informes y Estudios Gloobal. Instituto de Estudios Políticos para América Latina y África. Recuperado de http://www. gloobal.net/iepala/gloobal/fichas/ficha.php?entidad $=$ Textos\&id $=636$ \&opcion=documento

Bisang, R.y Gutman, G. (2000). La oferta tecnológica de las principales cade- 
nas agroindustriales en el Mercosur ampliado. Montevideo: Programa Cooperativo para el Desarrollo Tecnológico Agroalimentario y Agroindustrial del Cono Sur [Procisur], Banco Interamericano de Desarrollo [BID]. Recuperado de http:// repositorio.cepal.org/bitstream/ handle/11362/11083/087115129 es.pdf; jsessionid =4D377A15E8D2 0B597B580BE30960D5D9?seque $\underline{\text { nce }=1}$

Briceño Ruiz, J. (2010). Venezuela y el proceso de construcción del modelo económico del Mercosur. Cuadernos sobre Relaciones Internacionales, Regionalismo y DesarroIlo, 5(10), 85-111.

Buzan, B. (2004). The United States and the great powers. Cambridge: Polity Press.

Cascante Segura, C. H. (2014) Entre bloques y discursos: los procesos de alianza y disputa en América Latina. En W. Soto Acosta (Ed.), Política Internacional e Integración Regional Comparada en América Latina (pp. 35-44). San José: Facultad Latinoamericana de Ciencias Sociales [Flacso].

Cárdenas, E. J. (2005). Debate sobre reforma del Consejo de Seguridad de las Naciones Unidas. Agenda Internacional, 1(4), 90-98.

Cervo, A. L. (2009). La construcción del modelo industrialista brasileño. Revista DEP, Diplomacia, Estrategia y Política, 10, 74-86.

Chen, L. y De Lombaerde, P. (2014). Testing the relationships between globalization, Regionalization and regional hubness of the BRICS. Journal of Policy Modeling, 26(1), 111-131.

Cisneros, E. (2005). Debate sobre reforma del Consejo de Seguridad de las Naciones Unidas. Agenda Internacional, 1(4), 117-122.

Colombo, S. (2011). La política regional del gobierno de Néstor Kirchner. Política Externa, 21(1), 160-166. Recuperado de http://www.ieeiunesp.com.br/portal/wp-content/ uploads/2011/09/La-politica-regional-del-gobierno-de-Nestor-Kirchner-Sandra-Colombo.pdf

Da Silva, L. y Lagos, R. (10 de junio de 2014). América Latina: dos océanos, una voz. El País. Recuperado de http://puntolatino.ch/es/alianzadel-pacifico/7201-2014-prensaamerica-latina-dos-oceanos-unavoz-lula-da-silva-ricardo-lagos

Deciancio, M. (2016). Brazil's leadership through global channels. En S. Kingha, y C. Quiliconi (Eds.), Global and Regional Leadership of BRICS Countries (pp. 49-66). Nueva York: Springer.

Diamint, R. (2005). Debate sobre reforma del Consejo de Seguridad de Naciones Unidas. Agenda Internacional, 1(4), 98-103.

Durani, A. (2011). Regionalism and the drive toward liberalizing trade. Carleton College. Recuperado de http://people.carleton.edu

Elías, J. (2004). Deberíamos agradecer a los Estados Unidos. La Nación (Buenos Aires). Recuperado de 
http://www.lanacion.com.ar/641126deberiamos-agradecer-a-los-eeuu

Fermín, E. (2009). Alternativa bolivariana para los pueblos de nuestra América. Espacio Abierto, 18(2), 339-365.

Flemes, D. y Wehner, L. (2012). Drivers of strategic contestation in South America. GIGA Working Papers, (207). Recuperado de https:// www.files.ethz.ch/isn/15 $\underline{3968 /}$ wp207 flemes-wehner.pdf

Flemes, D. y Wojczewski, T. (2011). Contested leadership in comparative perspective. Asian Journal of Latin American Studies, 24(1), 1-27.

Flisfisch, A. (1 de octubre de 2011). La política exterior chilena y América del Sur. Estudios Internacionales, (168), pp. 115-141.

Fuentes, C. (2006). La apuesta por el poder blando: la política exterior de la Concertación, 2000-2006. En R. Funk (Ed.), El gobierno de Ricardo Lagos: la nueva vía chilena hacia el socialismo (pp. 1-22). Santiago de Chile: Editorial Universidad Diego Portales.

García, M. J. (2004). Trade in EU Foreign Relations. Post-Graduate Student Conference on European Foreign Policy, (july 2-3). Recuperado de http:Ise.ac.uk/international-relations/assets/...2004/ Garcia.doc

Garrido Rojas, J. (2001). Cambios socio-políticos en el escenario mundial (1945-2000). Santiago de Chile: Editorial Universitaria.
Garzón, J. F. (2015). Multipolarity and the Future of Regionalism. GIGA Working Paper, (264). Recuperado de https://giga-hamburg.de/en/system/files/publications/wp264 garzon.pdf

Giacalone, R. (2008). Motivaciones políticas para la constitución de la CSN. En R. Giacalone (Ed.), La integración sudamericana. Un complejo proceso inconcluso (pp. 17-49). Mérida: Universidad de Los Andes.

Giacalone, R. (2013). Venezuela en Unasur: integración regional y discurso político. Desafíos, 25(1), 129-163.

González, G. y Velázquez, R. (2013). La política exterior de México hacia América Latina en el sexenio de Felipe Calderón (2006-2012). Foro Internacional, LIII(3-4), 572-618.

González Ríos, I. (2014). Chile y Mercosur. Revisión de antecedentes con miras a la segunda década del siglo XXI. Recuperado de http:// sedici.unlp.edu.ar/bitstream/handle/10915/44709/Documento_completo.pdf?sequence $=1$

Granja Hernández, L. (2013). El Mercosur y sus asimetrías. Intersticios Sociales, (6), 1-29. Recuperado de http://www.scielo.org.mx/pdf/ins/ n6/n6a5.pdf

Granovsky, M. (9 de diciembre de 2004). El mensaje de Coricancha. Sindicato Mercosul, p. 12. Recuperado de http://.sindicatomercosul. $\underline{\text { com.br }}$ 
Gudynas, E. (2000). El acuerdo de libre comercio entre Chile y Estados Unidos anuncia retrocesos en la integración latinoamericana. CLAES D3E. Recuperado de http://integracionsur.com/alca/GudynasChileUsaAcuerdo.htm

Heilmann, S. y Schmidt, D. (2014). China's Foreign Political and Economic Relations. Maryland: Rowman \& Littlefield.

Hirst, M. (2009). La perspectiva sursur: la importancia del vínculo para Brasil. En G. Paz y R. Roett (Eds.), La presencia de China en el hemisferio occidental (pp. 117-136). Buenos Aires: Libros del Zorzal.

Hunter, R. (2001). Global economics and unstable regional geopolitics. En R. Kugler y E. Frost (Eds.), The Global Century. Vol. I (pp. 109125). Washington, D. C.: National Defense University Press.

Hveem, H. (2000). Explaining the regional phenomenon in an era of globalization. En R. Stubbs y G. R. Underhill (Eds.), Political economy and the changing global order (pp. 70-81). Don Mills: Oxford University Press.

lapadre, P. L. y Tajoli, L. (2014). Emerging Countries and Trade Regionalization. Journal of Policy Modeling, 26(1), 89-110. Recuperado de https://ideas.repec.org/a/ eee/jpolmo/v36y2014is1 ps89s110.html

Illera, O. (2005). La política exterior de Chávez: proyección de la revolución bolivariana en las relaciones internacionales. Desafíos, (12), 209-240.

Lapp, N. (2012). Resistance is util (Useful): Responses to brazilian hegemony. En K. P. Williams, S. E. Lobell y N. G. Jesse (Eds.), Beyond great powers and hegemons (pp. 145-160). Stanford: Stanford University Press.

Llenderrozas, E. (2013). Política exterior latinoamericana y la Comunidad de Estados Latinoamericanos y Caribeños. En A. Bonilla Soria y S. Álvarez Echandi (Eds.), Desafíos estratégicos del regionalismo contemporáneo (pp. 129-149). San José: Facultad Latinoamericana de Ciencias Sociales [Flacso].

Loza, J. (2005). La construcción de un sueño. Buenos Aires: IAES.

Malamud, A. (2011). A leader without followers? The growing divergence between the regional and global performance of brazilian foreign policy. Latin American Politics and Society, 53(3), 1-24. DOI: https://doi.org/10.1111/j.15482456.2011.00123.x

Malamud, A. (2016a). Latin American Regionalism Faces the Rise of Brazil. En G. I. Gardini y M. H.T. Almeida (Eds.), Foreign policy responses to the rise of Brazil (pp. 214-226). Nueva York: Palgrave Macmillan.

Malamud, A. (2016b). El malentendido latinoamericano. Nueva Sociedad, (266), 32-44.

Manger, M. (2009). Investing in protection: The politics of preferential 
trade agreements between north and South. Cambridge: Cambridge University Press.

Marticorena, J. (5 de agosto de 2000). Mercosur, del dicho al hecho... Sofofa. Recuperado de http://www. sofofa.cl/opinion/2000/comercioexterior/5-8-2000/quepasa22.htm

Merke, F. (2008). Identidad y política exterior. La Argentina y Brasil en perspectiva histórica. Sociedad Global, 2(1-2), 142-161. Recuperado de http://eumed.net/rev/sg/02/ fm.htm

Miranda, R. (2017). Los países emergentes en el G20 y la política seguida por Argentina. Oasis, 25, 129-148. DOI: https://doi. org/10.18601/16577558.n25.08

Mylonas, H. y Yorulmazlar, E. (2012). Regional multilateralism. Recuperado de http://globalpublicsquare. blogs.cnn.com/2012/01/14/regional-multilateralism-should-be-thenext-paradigm-in-global-affairs/

O'Connor, E. (2010). El neodesarrollismo brasileño como propuesta de desarrollo para Argentina. Economic Studies of International Development, 10(2), 55-80.

Onuki, J.; Mouron, F. y Urdinez, F. (2016). Latin American perceptions of regional identity and leadership in comparative perspective. Contexto Internacional, 38(1), 433-465.

Paolino, C. (2014). Las transformaciones estructurales en el sector agroalimentario. Revista Paranaense de Desenvolvimento, 35(127), 79-97.
Pinheiro, L. (2000). Traídos pelo desejo: um ensaio sobre a teoria e a práctica da política externa brasileira contemporânea. Contexto Internacional, 22(20), 305-335.

Pinheiro, L. y Gaio, G. (20149. Cooperation for development: Brazilian regional leadership and global protagonism. Brazilian Political Science Review, 8(2), pp. 8-30.

Quenan, C. (2013). América Latina frente a la crisis económica internacional. IdeAs, (4), 1-19. Recuperado de http://ideas.revues.org/780

Quintanar, S. (2012). Convergencias y divergencias en las estrategias de integración y cooperación energética regionales de Venezuela y Brasil. En R. Bernal-Meza y S. Quintanar (Eds.), Regionalismo, orden mundial: Suramérica, Europa, China (pp. 241-283). Buenos Aires: Grupo Editorial Latinoamericano [GEL].

Regueiro, L. y Bárzaga, M. (2012). Unasur: propuesta y proceso. Quito: Fundación de Estudios, Acción y Participación Social [Fedaeps].

Reuters/EFE. (12 de octubre de 2006). La propuesta para unir la CAN y el Mercosur divide la Cumbre Sudamericana de Bolivia. El Mundo. Recuperado de http://www.elmundo. es/elmundo/2006/12/09/internacional/1165690075.html

Ribeiro, P.F. (2014). An amphibian party? Organisational change and adaptation in the brazilian workers' party, 1980-2012. Journal of 
Latin American Studies, 46(1), 87119. DOI: https://doi.org/10.1017/ $\underline{\text { S0022216X13001831 }}$

Riggirozzi, P. (2010). Region, Regionness, and Regionalism in Latin America. LATN Working Paper, (130). Buenos Aires: Facultad Latinoamericana de Ciencias Sociales [Flacso].

Russell, R. (2006). La integración en América Latina. Recuperado de http://www.flacsoandes. edu.ec/biblio/catalog/resGet. php?resld $=19800$

Russell, R. y Tokatlian, J. G. (2011). Percepciones argentinas de Brasil. Plataforma Democrática Working Paper, (19). Recuperado de http:// www.plataformademocratica.org/ Arquivos/Plataforma_Democratica_Working_Paper_19_2011_Espanhol.pdf

Sayago, S. (2014). El análisis del discurso como técnica de investigación cualitativa y cuantitativa en las ciencias sociales. Revista Cinta de Moebio, (49). Recuperado de http://www.facso.uchile.cl/publicaciones/moebio/49/sayago.html

Schiff, M. (2002). Chile's trade policy. Santiago de Chile: Banco Central de Chile Working Paper 101. Recuperado de http://si2.bcentral.cl/public/pdf/documentos-trabajo/pdf/ dtbc151.pdf

Serbin, A. (2010). Regionalismo y soberanía nacional en América Latina. CRIES, (15). Recuperado de http:// cries.org/wp-content/uploads/ 2010/09/Documentos-15-web.pdf
Serbin, A. (2013). Los nuevos regionalismos y la Celac. En A. Bonilla Soria y S. Álvarez Echandi (Eds.), Desafíos estratégicos del regionalismo contemporáneo (pp. 47-78). San José: Facultad Latinoamericana de Ciencias Sociales [Flacso].

Sindicato Mercosur (9 de diciembre de 2004). El nacimiento de la comunidad Sudamericana. Recuperado de http://sindicatomercosul.com.br

Souza, A.de M., Oliveira, T.M. y Gonçalvez, S.S. (2010). Integrando desiguais: assimetrias estruturais e políticas de integraçao no Mercosul. Texto para Discussão 1477. Rio de Janeiro: Instituto de Pesquisa Econômica Aplicada [IPEA].

Stallings, B. (2009). El triángulo entre Estados Unidos, China y América Latina. En G. Paz y R. Roett (Eds.), La presencia de China en el hemisferio occidental (pp. 239-316). Buenos Aires: Libros del Zorzal.

Tovías, A. (2008). The brave new world of cross-regionalism. CEPII Working Paper, (2008-3). Recuperado de http://www.cepii.fr/pdf pub/ wp/2008/wp2008-03.pdf

Van Klaveren, A. (1998). Inserción internacional de Chile. En C. Toloza y E. Lahera (Eds.), Chile en los noventa (pp. 21-50). Chile: Presidencia de la República, Dirección de Estudios.

Venezuela, Ministerio de Relaciones Exteriores (2006). Libro Amarillo correspondiente al Ejercicio Fiscal del año 2005. Caracas: Ministerio de Relaciones Exteriores 
Vieira, M. A. y Alden, C. (2011). India, Brazil, and South Africa (IBSA). Global Governance, (17), 507-528.

Wehner, L. (2015). Role expectations as foreign policy: South American secondary powers' expectations of Brazil as a regional power. Foreign Policy Analysis, 11(4), 435455. DOI: https://doi.org/10.1111/ fpa. 12048
Womack, B. (2007). Teoría de la asimetría y poderes regionales: los casos de India, Brasil y Sudáfrica. En J. G. Tokatlian (Ed.), India, Brasil y Sudáfrica. El impacto de las nuevas potencias regionales (pp. 15-34). Buenos Aires: Libros del Zorzal.

Womack, B. (2016). Asymmetry and International Relationships. Nueva York: Cambridge University Press. 